\title{
Assessment of Nurses' Knowledge of Patient Care After Cardiac Catheterization in Mosul Hospitals
} \author{
F Abdulgani ${ }^{3}$ \\ ${ }^{1}$ Clinical Nursing Department, Faculty of Nursing, Mosul University, Iraq. \\ ${ }^{2}$ Clinical Nursing Department, Faculty of Nursing, Ninevah University, Iraq. \\ ${ }^{3}$ Ninevah Health Directorate, Mosul, Iraq \\ *Corresponding author.Email: hanady.jabbar@uoninevah.edu.iq
}

Hanady J Mahmood ${ }^{1,2, *}$, Radhwan H Ibrahim ${ }^{1,2}$, Ekhlas T Hassan ${ }^{1}$, and Mohammed

\begin{abstract}
Heart diseases can be diagnosed and evaluated using cardiac catheterization, which requires standardized policies of care. Cardiac catheterization needs qualified and skilled healthcare providers for excellent management outcomes. The current study aims to assess the nurses' knowledge of patient care after cardiac catheterization. The descriptive crosssectional study was designed - the study sample consists of (110). The study setting is in Mosul Hospital. Data were collected for the period (20th February 2019) to (22th March 2019). A questionnaire depends on the interview style; the survey designed to achieve the study's objective consisted of three parts: the first content was demographic information ( 6 items). The second part includes the general knowledge of nurses about cardiac catheterization (10 items). The third part consists of the skill of the cardiac catheterization nurse(18 items). A descriptive statistical approach and an inferential analytical approach are used to analyze the data. The results showed that (56.4\%) males, females (43.6\%) were in the age of (25-29) years, most of the nurses had an experience of 1-5 years. The study showed a statistically significant relationship between the age of the nurse and their knowledge of the complications of cardiac catheterization $(\mathrm{P}=0.05)$. There is no statistically significant relationship between the gender of the nurses, education level, years of service in the nursing field, and experience. The study concluded that the sample percentage is high, and the result was is not acceptable for the level of knowledge regarding cardiac catheterization risk factors. The study recommended that nurses participate in training courses to improve nursing care provided to the patient and his family during cardiac catheterization.
\end{abstract}

Keywords: Cardiac Catheterization, Nurse, Knowledge, Patient care.

\section{INTRODUCTION}

The cardiovascular device helps supply the fast conduction of vitamins to the tissues in the body and permits the rapid elimination of unused products. There is no such structure in smaller, less complex organisms than the human body because their desires can meet with simple diffusion. The development of the cardiovascular device provided a competence in assisting the diffusion process, allowing the growth of more significant organisms [1]. The most common causes leading to death are cardiovascular diseases [2]. The World Health Organization reported 18 million loss of life from cardiovascular diseases in 2008 and was estimated to reach 23 million by 2030[3]. One of the most common and the best way to diagnose coronary artery diseases is
Coronary Angiography (C.A) [4]. The cardiac catheterization procedure is used for heart patients such as ischemic heart disease (IHD), coronary artery disease CAD, heart valves, and congenital heart disease because it takes a wide range and its advantages for short time.

Additionally, with the increasing population, the likelihood of desired health outcomes is consistent with current professional knowledge of the quality of health care services for patients with cardiac catheterization [5]. A catheter is a thin tube passed into the heart chambers via a vein or artery and is usually inserted through the thigh right or area of the radial [6]. Cardiac catheterization is an alternating plan that does not require prolonged bed rest and is related to reductions, puncture site complications, and hospital stay [7]. The nursing 
staff plays a dynamic role in monitoring and evaluating angina pectoris that recurs shortly after percutaneous coronary intervention and any chest pain requiring immediate and careful attention to the onset of blood vessel spasms or impended arteries blockage [8]. The Focusing on early priorities for nursing staff care for patients after Percutaneous Coronary Intervention includes determining physiological stability and patient comfort through combination bed technology, assessment, and monitoring; and also to need knowledge and competence regarding the efficacy of measures used to prevent complications of Post-Percutaneous Coronary Intervention [9]. The current study aims to assess the nurse's knowledge of patient care after cardiac catheterization in City of Mosul Hospitals.

\section{METHODOLOGY AND RESULTS}

A adopted the current study cross-sectional descriptive design to achieve the present study's objectives from (20th February 2019) to (20th April 2019). The research and data collection period (20th February 2019) (22th March 2019). Conducted the current study was in four hospitals, two on the right side of Mosul (Al-Jamhuri teaching Hospital and Mosul General Hospital) and two on the left side of Mosul (Al Salam hospital and Ibn-Sina Teaching Hospital). A selfdesigned data collection questionnaire was used to collect study information created based on previous studies and relevant literature. It is composed of three parts: - 1- part one: - this part includes (6) items that focus on the participant demographic data such as (age, sex, marital status, educational level, nursing years of experience, and participation in a heart catheter course). Part two consists of the general question to assess nurses' knowledge toward Cardiac Catheterization safety. Part three consists of (19) items to determine nurses' clinical practical knowledge about cardiac catheterization. The overall question is dependent on three options (Always, Sometimes, Never). A random sample was selecting the participation (110) of a nurse. The study's sample selection comprises male and female age groups between $(22->45)$ years. Knowledge level of was $(0-2)$ Fail, Not Acceptable $=(3-4)$, Acceptable $=(5)$, very Good $=(6-$ $7)$, very Good= (8-9), Excellent $=(10)$. The results of this study are shown in Table 1 to Table 3.

\section{DISCUSSION}

Nursing care is essential to prevent patients from experiencing complications post-cardiac catheterization and survival for a long time. Therefore, the competence of nurses in the knowledge of patient care after cardiac catheterization is critical.
Table 1. Demographical Characteristics of the Study Sample

\begin{tabular}{|c|c|c|c|}
\hline \multicolumn{2}{|l|}{ Demographical Item } & Freq. & \% \\
\hline \multirow{4}{*}{ Age } & $(20-24)$ & 23 & 20.9 \\
\cline { 2 - 4 } & $(\mathbf{2 5 - 2 9 )}$ & $\mathbf{4 4}$ & $\mathbf{4 0 . 0}$ \\
\cline { 2 - 4 } & $(30-34)$ & 21 & 19.1 \\
\cline { 2 - 4 } & $(35-40)$ & 14 & 12.7 \\
\cline { 2 - 4 } & $(40-44)$ & 2 & 1.8 \\
\cline { 2 - 4 } & $(45-50)$ & 6 & 5.5 \\
\hline \multirow{4}{*}{ Gender } & Male & $\mathbf{6 2}$ & $\mathbf{5 6 . 4}$ \\
\cline { 2 - 4 } & Female & 48 & 43.6 \\
\hline \multirow{3}{*}{ Marital Status } & Single & 35 & 31.8 \\
\cline { 2 - 4 } & Married & $\mathbf{7 3}$ & $\mathbf{6 6 . 4}$ \\
\cline { 2 - 4 } & Widowed & 2 & 1.8 \\
\hline \multirow{3}{*}{ Educational Level } & Junior & 20 & 18.2 \\
\cline { 2 - 4 } & Institute & 24 & 21.8 \\
\cline { 2 - 4 } & University & $\mathbf{6 2}$ & $\mathbf{5 6 . 4}$ \\
\cline { 2 - 4 } & Master & 4 & 3.6 \\
\hline \multirow{3}{*}{ Experience of work } & $(\mathbf{1 - 5})$ & $\mathbf{9 5}$ & $\mathbf{8 6 . 4}$ \\
\cline { 2 - 4 } & $(6-10)$ & 12 & 10.9 \\
\cline { 2 - 4 } & $(11-15)$ & 3 & 2.7 \\
\hline \multirow{3}{*}{ Training course } & Yes & 49 & 44.5 \\
\hline & No & $\mathbf{6 1}$ & $\mathbf{5 5 . 5}$ \\
\hline \multicolumn{2}{|c|}{ Total } & $\mathbf{1 1 0}$ & $\mathbf{1 0 0 . 0}$ \\
\hline
\end{tabular}

Table 2. The Samples' Knowledge Level Results about the risk factors of the cardiac catheterization

\begin{tabular}{|l|c|c}
\hline \multicolumn{1}{|c|}{ Estimate } & Freq. & \% \\
\hline Fail & 27 & 24.5 \\
\hline Not Acceptable & $\mathbf{5 3}$ & $\mathbf{4 8 . 2}$ \\
\hline Acceptable & 17 & 15.5 \\
\hline Good & 12 & 10.9 \\
\hline very Good & 1 & 0.9 \\
\hline Excellent Total & 0 & 0 \\
\hline \multicolumn{1}{|c|}{110} & 100.0 \\
\hline
\end{tabular}

Fail $=(0-2)$, Not Acceptable $=(3-4)$, Acceptable $=(5)$, very Good $=(6-7)$, very Good $=(8-9)$, Excellent $=(10)$

Table 3. Statistical Differences of Demographic Characteristics Result and Samples' Knowledge about patient care after cardiac catheterization

\begin{tabular}{|l|l|l|l|l|l|l|}
\hline \multirow{2}{*}{ Descriptive Statistics } & \multicolumn{2}{|c|}{ Years of service } & \multicolumn{2}{|c|}{$\begin{array}{c}\text { Experience of } \\
\text { work }\end{array}$} & \multicolumn{2}{|c|}{ Training course } \\
\cline { 2 - 8 } & P. value & Sig & P. value & Sig & P. value & Sig \\
\hline Total Knowledge & $\mathbf{0 . 0 0 8}$ & $\mathbf{S}$ & 0.120 & NS & 0.473 & NS \\
\hline Explain the post procedure care & $\mathbf{0 . 0 0 6}$ & $\mathbf{S}$ & 0.175 & NS & $\mathbf{0 . 0 0 0}$ & S \\
\hline Remove the sheath & 0.576 & NS & 0.167 & NS & 0.686 & NS \\
\hline $\begin{array}{l}\text { Observe the catheter site } \\
\text { insertion }\end{array}$ & $\mathbf{0 . 0 0 8}$ & $\mathbf{S}$ & 0.079 & NS & 0.014 & NS \\
\hline Assess the vital sign & 0.774 & NS & 0.900 & NS & 0.290 & NS \\
\hline $\begin{array}{l}\text { Assess the skin color or } \\
\text { temperature }\end{array}$ & $\mathbf{0 . 0 2 6}$ & $\mathbf{S}$ & 0.304 & NS & 0.115 & NS \\
\hline Assess for stability of pain & 0.162 & NS & $\mathbf{0 . 0 3 0}$ & S & 0.354 & NS \\
\hline Monitor the patient by ECG & 0.167 & NS & $\mathbf{0 . 0 4 6}$ & S & 0.300 & NS \\
\hline $\begin{array}{l}\text { Places the patient in a supine } \\
\text { position }\end{array}$ & 0.682 & NS & 0.694 & NS & 0.115 & NS \\
\hline $\begin{array}{l}\text { Encourage patient to increased } \\
\text { fluid intake }\end{array}$ & 0.380 & NS & 0.328 & NS & 0.860 & NS \\
\hline $\begin{array}{l}\text { Observe for signs of } \\
\text { hypersensitivity }\end{array}$ & 0.191 & NS & 0.151 & NS & 0.391 & NS \\
\hline Check the patient output & 0.985 & NS & 0.593 & NS & 0.425 & NS \\
\hline $\begin{array}{l}\text { Observe the extremity of } \\
\text { catheter inserted }\end{array}$ & 0.127 & NS & $\mathbf{0 . 0 2 7}$ & S & 0.144 & NS \\
\hline $\begin{array}{l}\text { Immobilizes the arm-on-arm } \\
\text { board }\end{array}$ & 0.933 & NS & 0.608 & NS & 0.135 & NS \\
\hline $\begin{array}{l}\text { Instruct the patient to cough on } \\
\text { need }\end{array}$ & 0.233 & NS & 0.186 & NS & 0.384 & NS \\
\hline $\begin{array}{l}\text { Pressure dressing over the } \\
\text { insertion site }\end{array}$ & 0.519 & NS & 0.151 & NS & 0.174 & NS \\
\hline $\begin{array}{l}\text { Applies firm pressure over the } \\
\text { site }\end{array}$ & $\mathbf{0 . 0 1 2}$ & $\mathbf{S}$ & 0.114 & NS & 0.197 & NS \\
\hline $\begin{array}{l}\text { Monitor intake output after } 24 \\
\text { hours }\end{array}$ & 0.145 & NS & 0.942 & NS & 0.138 & NS \\
\hline $\begin{array}{l}\text { Instruct the pt. for self- } \\
\text { management at home }\end{array}$ & 0.443 & NS & 0.267 & NS & $\mathbf{0 . 0 0 5}$ & S \\
\hline
\end{tabular}


The result of the study sample showed that the majority (44\%) was in the age group (25-29) years old, and the lowest (2\%) was in the age group (40-44). Most of the study sample $(56.4 \%)$ are males, and the rest $(43.6 \%)$ are female; this finding is supported by [10][13], who concluded that the most of study nurses were male, but they differed with the result of [14], [15] showed in their studies that most nurses were female. The present study showed that most participants hold a technical institute degree and a bachelor's degree in nursing regarding educational level. This finding supported a study conducted in Eygpt by [15], who studied nurses' knowledge and practiced the implant device, found that the majority of the sample had bachelor and technical institute of nursing. Another study showed conflict through [16], [17] they showed that most of their studied samples were diplomas in nursing. Also, [13], [18] found that the highest percentage of nurses were secondary school nurses. Regarding the years of general nursing services, $(86.4 \%)$ of the sample was from (1-5) years. These findings contradict the study done in Baghdad [19], which indicated that the maximum percentage of experience years ranged among (1-10) years. However, another study result finding supports [10] that no training sessions are given regarding cardiac catheterization for most study samples $(55.5 \%)$.

The questionnaire results demonstrated that nurses working in medical and surgical ward nurses' Knowledge of Patient Safety After Cardiac Catheterization were unacceptable. This finding disagrees with other studies done in Al-Najaf All-Ashraf City, which shows nurses' knowledge regarding cardiac patient care was good [13]. This finding is inconsistent with a cross-sectional study done in Pakistan showing that registered nurses have the correct level of knowledge regarding cardiac catheter care patients [20]. There were no statistically significant differences with the average knowledge scores with years of experience for the nurses. This result is inconsistent with the [21] study, which revealed a high relationship between practice scores and work experience. [22] An evaluation of nurse care practices provided to patients who underwent open-heart surgery in the Sulaimani Center of Heart Diseases showed a significant statistical association between nurses' training and experience years. Besides, [23] It was reported that the level of knowledge is higher for nursing staff nurses with more than five years of experience compared to those with less than five years of experience. Finally, [20] showed a statistically significant relationship between knowledge and practice, knowledge and qualification. This result indicated that ability greatly influences nurses' knowledge, and nurses can develop their knowledge through experience.

The researchers believe that this finding is related to data collection from nurses working in hospitals in the City of Mosul, not just nurses working in the coronary care unit. In general, in Iraq, nurses do not have a subspecialty in nursing care; Also, barriers to the way nurses study and obtain a high degree about their specialty is a significant problem for nurses.

\section{CONCLUSION}

The current study shows that most of the study sample was male. The ages of the study sample members ranged between (25-29) years. The study shows a high percentage of those selected did not participate in training courses for cardiac catheterization. The high passage rate was not acceptable for knowledge of the level of nursing care after cardiac catheterization for patients with heart diseases.

\section{Recommendation}

The current study recommended developing an educational training program for nurses working in the field of cardiac catheterization. Nursing schools should pay more attention to cardiac catheterization and postcatheter care. Set a plan to program for postgraduate study means graduating nurses who specialize in cardiac catheterization. Nursing schools should pay more attention to cardiac catheterization and patient care after catheterization. Set a plan to program for postgraduate study means graduating nurses who specialize in cardiac catheterization.

\section{AUTHORS' CONTRIBUTIONS}

Mahmood was responsible for the study concept, design, and data collection. Ibrahim and Abdulgani analyzed the data, drafted the manuscript, and complete critical reviews to the paper for significant intellectual content and, in addition, to provide statistical expertise. while, Hassan provided administrative, technical support.

\section{ACKNOWLEDGMENTS}

The authors thank all participating nurses at hospitals in Mosul City, Iraq, for their support in completing this research.

\section{REFERENCES}

[1] J. D. W. Evans, D. Horton-Szar, and D. E. Newby, Crash Course Cardiovascular System Updated Edition - E-Book. Elsevier Health Sciences, 2015.

[2] N. JAMSHIDI, A. ABBASZADEH, and K. M. NAJAFI, "The effects of video education on comfort and tolerability of patients undergoing coronary angiography," 2010.

[3] "Cardiovascular diseases." https://www.who.int/health-topics/cardiovasculardiseases\#tab=tab_1 (accessed Aug. 05, 2021).

[4] T. Moradi and H. M. ADIB, "The effect of a multimodal preparation package on anxiety in patients undergoing coronary angiography," 2015.

[5] M. J. Kern, P. Sorajja, and M. J. Lim, Cardiac 
catheterization handbook. Elsevier Health Sciences, 2015.

[6] M. M. Mobley, R. E. Stroup, and S. F. Kaine, "Comparative risk of cardiac catheterisations performed on low birth weight neonates," Cardiol. Young, vol. 23, no. 5, pp. 722-726, 2013.

[7] G. Steffenino et al., "Vascular access complications after cardiac catheterisation: a nurse-led quality assurance program," Eur. J. Cardiovasc. Nurs., vol. 5, no. 1, pp. 31-36, 2006.

[8] P. G. Morton, D. K. Fontaine, C. M. Hudak, and B. M. Gallo, Critical care nursing: a holistic approach, vol. 1. Lippincott Williams \& Wilkins Philadelphia, 2005.

[9] G. I. Peet, M. A. McGrath, J. H. Brunt, and J. D. Hilton, "Femoral arterial sheath removal after PTCA: A cross-Canada survey.," Can. J. Cardiovasc. nursing $=J$. Can. en soins Infirm. cardio-vasculaires, vol. 6, no. 3-4, pp. 13-19, 1995.

[10] N. K. Hassan and L. F. Aburaghif, "Effectiveness of an Educational Program on Nurse' s knowledge concerning Complications of Cardiac Catheterization among Children at Al-Nassirhya Heart Center .,"Kufa Journal for Nursing Sciences, vol. 6, no. 3, pp. 161-171, 2016.

[11] M. A. al-K. M. Al, "Janabi: Assessment of Nurses' Knowledge towards Cardiopulmonary Resuscitation." Dissertation) Baghdad University, Nursing College, 2012.

[12] S. Hassan and H. Hassan, "Effectiveness of nursing education program on nurses knowledge toward Arrhythmia in Kirkuk's teaching hospitals," Coll. Nursing, Univ. Kirkuk.. Kufa J. Nurs. Sci., vol. 2, no. 3, pp. 56-64, 2012.

[13] D. Al-Ftlawy, "Determination of nurses' knowledge toward care provided to patients with acute myocardial infarction in Al-Najaf City," kufa $J$. Nurs. Sci., vol. 2, no. 2, pp. 11-13, 2014.

[14] S. Parajulee and V. Selvaraj, "Knowledge of nurses towards cardiopulmonary resuscitation in a tertiary care teaching hospital in Nepal," J. Clin. Diagnostic Res., vol. 5, no. 8, pp. 1585-1588, 2011.

[15] N. S. Ali, W. Youssef, A. Mohamed, and A. Hussein, "Nurses' knowledge and practice regarding implantable cardiac devices in Egypt," Br. J. Card. Nurs., vol. 10, no. 1, pp. 34-40, 2015.

[16] A. H. Abudahi, "Relationship between perceived organizational climate and conflict management strategies among nurses in Cairo University Hospital: Piloting a conflict management approach," CU Theses, 2012.

[17] H. A. Elfeky and F. S. Ali, "Nurses' practices and perception of delirium in the intensive care units of a selected university hospitals in Egypt," J. Educ.
Pract., vol. 4, no. 19, pp. 61-70, 2013.

[18] H. Mohammed and H. Atiyah, "Nurses, knowledge concerning an implantation pacemaker for adult patients with cardiac rhythm disorder at $\mathrm{Al}$ Nassirrhyia Heart Center," Kufa J. Nurs. Sci., vol. 6, no. 1, pp. 216-223, 2016

[19] S. M. Zaki, "Evaluation of Nurses' Practices toward Children undergoing Cardiac Catheterization," Iraqi Sci. Nurs. J., vol. 23, no. 2, pp. 83-90, 2010.

[20] M. Feroze, M. Afzal, H. Sarwar, A. Galani, and S. Afshan, "Knowledge and Practice of Registered Nurses about Patient Safety after Cardiac Catheterization in Punjab Institute of Cardiology Hospital in Lahore, Pakistan," Int. J. Musculoskelet. Pain Prev., vol. 2, no. 2, pp. 233-238, 2017.

[21] M. P. THOMAS, "A study to evaluate the effectiveness of video assisted teaching programme on knowledge and practice regarding cardioversion and defibrillation among staff nurses working in cardiac unit in selected hospitals of Bagalkot.” 2013.

[22] S. Aziz and S. Lafi, "Evaluation of Nurses' practices provided to the Patients who undergo Open Heart Surgery in Sulaimani center of Heart Diseases (SCHD)," Kufa J. Nurs. Sci., vol. 3, no. 1, pp. 7480, 2011

[23] S. R. Arathy, "A study to assess the knowledge and practices among cardicac nurses about patients safety after cardiac catheterisation," 2011 